\title{
Electronic characteristics of asymmetric triple GaAlAs/GaAs and GaInAs/GaAs quantum wells depending on Al and In concentration
}

\author{
Ozan Ö̈türk ${ }^{1 *(D)}$, Emine Ö̈türk ${ }^{2}$, Sezai Elagöz ${ }^{3}$ \\ ${ }^{1}$ Sivas Cumhuriyet University, Department of Nanotechnology Engineering, 58140, Sivas-TURKEY \\ ${ }^{2}$ Sivas Cumhuriyet University, Department of Physics, 58140, Sivas-TURKEY \\ ${ }^{3}$ ASELSAN - Microelectronics, Guidence \& Electro-Optics, Ankara-TURKEY
}

\begin{abstract}
Herein, the electronic characteristics of asymmetric triple Ga1-x Alx As/GaAs quantum wells (A model) and Ga1-x Inx As/GaAs quantum wells (B model) have been examined as dependent on $\mathrm{Al}$ and In concentration. The energy levels, the wave functions and the finding probability of electron in quantum well $(\mathrm{QW})$ of these systems under effective mass approach were concluded by Schrödinger equation solution. According to our results, the main differences between models $\mathrm{A}$ and $\mathrm{B}$ are effective mass and energy gap. For A model, GaAlAs is the barrier and GaAs is the well. Whereas for B model, GaAs is the barrier and GaInAs is the well. Also, the energy levels and the potential height of B model are unceasingly higher than of $\mathrm{B}$ model. The concentration ratio has a great impact on the electronic features of the asymmetric triple quantum well (ATQW). These features have a convenient attention for the purpose of adjustable semiconductor devices.
\end{abstract}

\section{Article info \\ History:}

Received:28.11.2019

Accepted:19.02.2020

Keywords:

Asymmetric triple

GaAlAs/GaAs quantum

well,

Asymmetric triple

GaInAs/GaAs quantum well,

Concentration ratio,

Electronic

characteristics.

\section{Introduction}

The electronic characteristics of the lowdimensional structures (LDSs) are extremely reliant on the pressure of the asymmetry of the potential profile of a semiconductor quantum well (QW). Such asymmetry of the potential shape could be provided by an electric field or the potential profile may be altered by an alloy ratio. We are concerned in observing the structure of an asymmetric triple quantum wells (ATQW) formed by two different semiconductors (e.g, GaAs/GaAlAs and InGaAs/GaAs). These structures contain three QWs coupled by two barriers. They are very suitable structure for observing quantum electronic transport. Because GaAlAs / GaAs QW systems are applied in modern photo-electronics and high-speed electronic devices, the electrical and optical properties of the related systems have been widely investigated under both the pressure and external fields [1-6]. The segregation of indium atoms in the GaInAs layer has been extensively researched in current times, as the considerate of high-performance devices desires sudden hetero-interfaces [7-11]. These indium atoms are powerfully related to the growth temperature and the GaInAs/GaAs structure is allocated from the growing surface throughout MBE growth.

ATQW structures are the ultimate structures for examining the mechanisms of carrier transfer [1214], related to single and double QWs. These systems are very motivating for the device industry because by the interlayer distance between QWs and the barrier alters, a development in the transport features is realized. The focus benefit of asymmetric multiple quantum well (AMQW) semiconductors over single QW is the advanced exciton electro-optic reply. The opto-electronic features of the excitons in AMQWs ensure a range of potential practices in high-speed spatial light modulators and switches. This study focused on the theoretical research of the electronic qualities of $\mathrm{Ga}_{1-\mathrm{x}} \mathrm{Al}_{\mathrm{x}} \mathrm{As} / \mathrm{GaAs}$ ATQWs and $\mathrm{Ga}_{1-\mathrm{x}} \mathrm{In}_{\mathrm{x}} \mathrm{As} / \mathrm{GaAs}$ 
ATQWs depending on the $\mathrm{x}$-concentration (where $\mathrm{X}$ represents the contribution rate of $\mathrm{Al}$ and $\mathrm{In}$ in ATQW, individually). A model and B model will be named for $\mathrm{Ga}_{1-\mathrm{x}} \mathrm{Al}_{\mathrm{x}}$ As/GaAs ATQWs and $\mathrm{Ga}_{1-}$ ${ }_{x} \mathrm{In}_{\mathrm{x}} \mathrm{As} / \mathrm{GaAs} \mathrm{ATQWs}$, correspondingly. There are on the left hand side "semi parabolic QW", the middle hand side "semi half inverse parabolic-half parabolic QW" and on the right hand side "semi inverse parabolic QW". The motivation for using many ATQWs with different images is to create multi wavelength optical devices.

\section{Materials and Methods}

Under the effective-mass approach, the wave functions and the energy levels for electrons in ATQW could be realized by dissolving the one-dimensional Schrödinger equation.

$$
\left(-\frac{\hbar^{2}}{2 m^{*}} \frac{d^{2}}{d^{2}}+V(z)\right) \Psi(z)=E \Psi(z)
$$

where $\mathrm{V}(\mathrm{z})$ is the confined potential, and $\mathrm{E}$ and $\Psi(\mathrm{z})$ are the eigen-energy and eigen-function of the Eq. (1) solution.

The confinement potential of ATQW for the particle $z$-direction, $b_{L}$ and $b_{R}$ being the left and right barrier widths, $L_{L}, L_{M}$ and $L_{R}$ being the left, middle and the right quantum widths, respectively, are given by

$$
\mathrm{V}(\mathrm{z})=\mathrm{V}_{0}\left\{\begin{array}{lr}
\frac{2}{\mathrm{~L}_{\mathrm{L}}^{2}}\left(\mathrm{z}+\mathrm{b}_{\mathrm{L}}+\frac{\left(\mathrm{L}_{\mathrm{M}}+\mathrm{L}_{\mathrm{L}}\right)}{2}\right)^{2} & -\left(\mathrm{L}_{\mathrm{L}}+\mathrm{b}_{\mathrm{L}}+\frac{\mathrm{L}_{\mathrm{M}}}{2}\right) \leq \mathrm{z} \leq-\left(\mathrm{b}_{\mathrm{L}}+\frac{\mathrm{L}_{\mathrm{M}}}{2}\right) \\
-\frac{2}{\mathrm{~L}_{\mathrm{M}}^{2}} \mathrm{z}^{2}+\frac{1}{2} & -\frac{\mathrm{L}_{\mathrm{M}}}{2} \leq \mathrm{z} \leq 0 \\
\frac{2}{\mathrm{~L}_{\mathrm{M}}^{2}} \mathrm{z}^{2} & 0 \leq \mathrm{z} \leq \frac{\mathrm{L}_{\mathrm{M}}}{2} \\
-\frac{2}{\mathrm{~L}_{\mathrm{R}}^{2}}\left(\mathrm{z}-\mathrm{b}_{\mathrm{R}}-\frac{\left(\mathrm{L}_{\mathrm{M}}+\mathrm{L}_{\mathrm{R}}\right)}{2}\right)^{2}+\frac{1}{2} & \frac{\mathrm{L}_{\mathrm{M}}}{2}+\mathrm{b}_{\mathrm{R}} \leq \mathrm{z} \leq \frac{\mathrm{L}_{\mathrm{M}}}{2}+\mathrm{b}_{\mathrm{R}}+\mathrm{L}_{\mathrm{R}} \\
1 & \text { elsewhere }
\end{array}\right.
$$

The discontinuity in the conduction band edge and the effective mass of electron of $\mathrm{Ga}_{1-\mathrm{x}} \mathrm{Al}_{\mathrm{x}} \mathrm{As} / \mathrm{GaAs}[15-17]$ and $\mathrm{Ga}_{1-\mathrm{x}} \mathrm{In}_{\mathrm{x}} \mathrm{As} / \mathrm{GaAs}[15-16,18]$ are analyzed using the next equations.

$$
\begin{aligned}
& \mathrm{m}_{\mathrm{GaAlAs}}^{*}=(0.067+0.083 \mathrm{x}) \mathrm{m}_{0} \\
& \mathrm{~m}_{\text {GaInAs }}^{*}=(0.067-0.04 \mathrm{x}) \mathrm{m}_{0} \\
& \mathrm{~V}_{0}^{\mathrm{GaAlAs}}=0.6\left(\mathrm{E}_{\mathrm{g}}^{\mathrm{GaAlAs}}-\mathrm{E}_{\mathrm{g}}^{\mathrm{GaAs}}\right) \\
& \mathrm{V}_{0}{ }^{\mathrm{GaInAs}}=0.6\left(\mathrm{E}_{\mathrm{g}}^{\mathrm{GaAs}}-\mathrm{E}_{\mathrm{g}}^{\mathrm{GaInAs}}\right)
\end{aligned}
$$

Where $\quad \mathrm{E}_{\mathrm{g}}^{\mathrm{GaAlAs}}=\left(\mathrm{E}_{\mathrm{g}}^{\mathrm{GaAs}}+1247 \mathrm{x}\right) \mathrm{meV}, \quad \mathrm{E}_{\mathrm{g}}^{\mathrm{GaInAs}}=\left(\mathrm{E}_{\mathrm{g}}^{\mathrm{GaAs}}-1619 \mathrm{x}+555 \mathrm{x}^{2}\right) \mathrm{meV}, \quad \mathrm{E}_{\mathrm{g}}^{\mathrm{GaAs}}=$ $1424 \mathrm{meV}$, and $\mathrm{m}^{*}$ is the effective mass depending on the material composition.

The QW confined potential is essential for the limitation of the electrons. Therefore, the finding probability of the electron in different QWs is provided by,

$$
\mathrm{P}_{\mathrm{i}}^{\mathrm{W}}=\int\left|\Psi_{\mathrm{i}}^{\mathrm{W}}(\mathrm{z})\right|^{2} \mathrm{dz} \quad(\mathrm{i}=1,2,3 ; \quad \mathrm{W}=\mathrm{L}, \mathrm{M}, \mathrm{R})
$$

where L, M and R indicate the left QW (LQW), the middle QW (MQW) and the right QW (RQW), correspondingly. 


\section{Results and Discussion}

It has been notionally examined the electronic features of A and B models depending on the $\mathrm{X}$ concentration for ATQW. In this study, all well widths are $\mathrm{L}_{\mathrm{L}}=\mathrm{L}_{\mathrm{M}}=\mathrm{L}_{\mathrm{R}}=8 \mathrm{~nm}, \mathrm{~b}_{\mathrm{L}}=\mathrm{b}_{\mathrm{R}}=$ $2 \mathrm{~nm}$ and $\mathrm{T}=300 \mathrm{~K}$.

For different x-values, Fig. 1 (A model) and Fig. 2 (B model) demonstrate the confinement potential, the bound energy levels and squared wave functions referred to these energy levels. As understood from Eq. (3) and Eq. (4), the major differences of A and B type are the effective mass and the energy gap. While for A model the well is GaAs and the barrier is GaAlAs, for B model the well is GaInAs and the barrier is GaAs. As estimated, the energy levels of A model with lower potential height are continuously lower than the energy levels of B model. As can be seen from these figures, there are three, four and five energy states in A structure for $\mathrm{x}=0.10, \mathrm{x}=0.15$ and $\mathrm{x}=$ 0.20 respectively, whereas $B$ structure with the same ratios has three, three and four confined energy levels, respectively. For both models, the electron in the ground state is commonly located in LQW, while the electrons at the second and third energy levels are encircled in MQW and RQW, respectively. As the height of the potential profile changes depending on the concentration ratio, both the bound state energy levels and the probability

densities of electrons at these energy levels change. The sensitivity of A model to the $\mathrm{X}$ concentration ratio appears to be higher than $\mathrm{B}$ model.

For structure A and B, the resulting bounded state energy levels corresponding to the change in the concentration ratio between $\mathrm{x}=(0.10-0.25)$ are given in Fig. 3a and Fig. 3b, serially. As expected, as the concentration ratio increases, the height of the limited potential and consequently the values of the energy levels increase, and more confined state energy levels exist in QWs. The fourth bound state energy is seen at $x \geq 0.15$ in A structure and $x \geq$ 0.16 in B structure. In A model, the fifth energy level was found within the enclosed potential at $x \geq 0.20$, whereas this energy level appeared in the $\mathrm{B}$ model at $\mathrm{x} \geq 0.24$. The differences are due to the fact that the effective mass of the electron in $\mathrm{B}$ structure is smaller than A structure and thus the energy levels rise to higher values. Therefore, if it is desired to obtain more bound state energy levels depending on the $\mathrm{x}$-concentration value, then $\mathrm{A}$ model should be preferred.

In Fig. 4a and Fig. 4b, the finding probability of the electrons in LQW, MQW and RQW for first three bounded energy states as a function of the $\mathrm{x}$ concentration is shown for both A and B model, respectively.
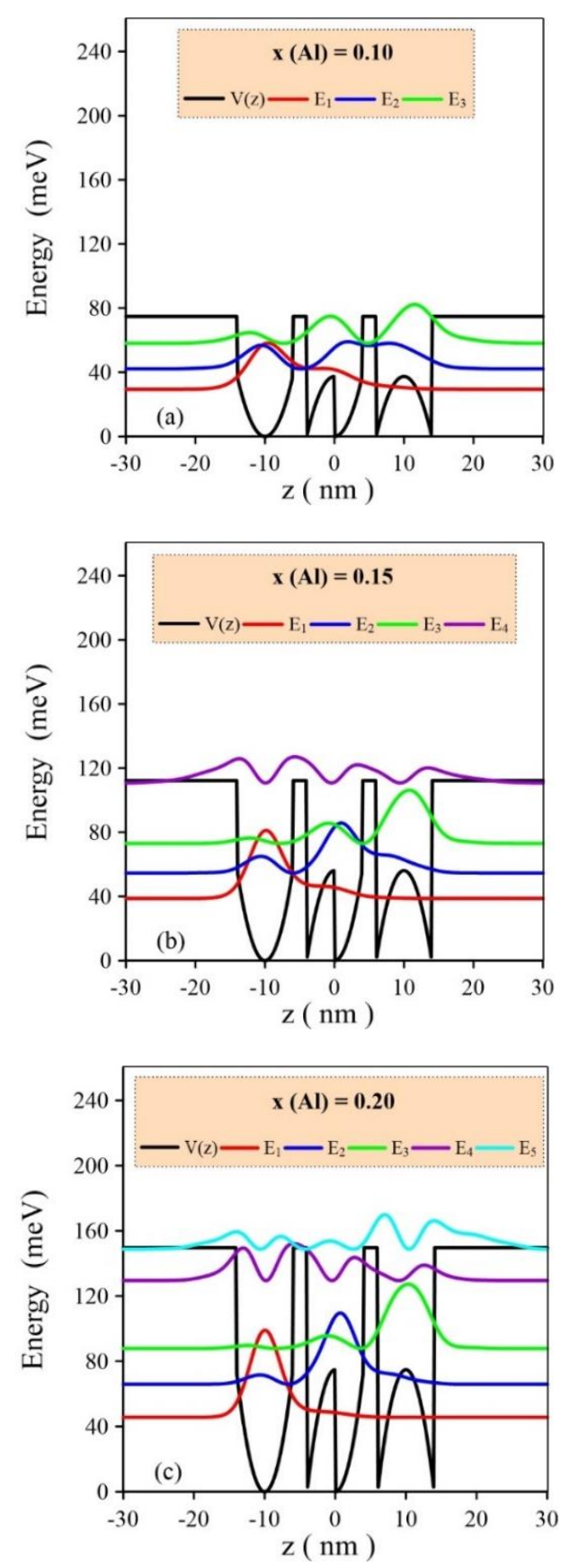

Figure 1. For ATQW (A model), the confined potential and the bound energy levels with their squared wave functions for a) $\mathrm{x}=0.10, \mathrm{~b}) \mathrm{x}=0.15, \mathrm{c}) \mathrm{x}=0.20$. 

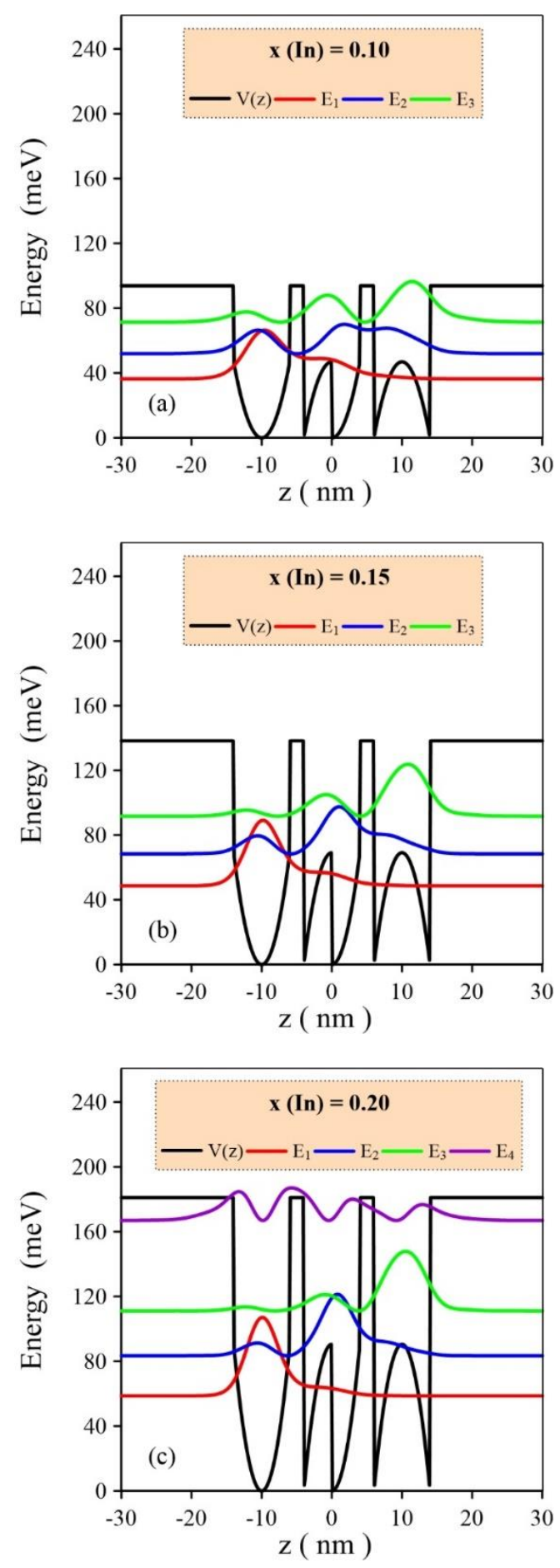

Figure 2. For ATQW (B model), the confined potential and the bound energy levels with their squared wave functions for a) $x=0.10, b) x=0.15, c) x=0.20$.
In both models, for the first value $\mathrm{x}=0.10$, the ground, second and third state energy levels are located in LQW, MQW and RQW, respectively, and these probability densities in the same QWs rise as the concentration ratio increases. The probability densities in B model is slightly lower than A model.

\section{Conclusions}

In present work, the electronic qualities of asymmetric triple $\mathrm{Ga}_{1-\mathrm{x}} \mathrm{Al}_{\mathrm{x}} \mathrm{As} / \mathrm{GaAs}$ and $\mathrm{Ga}_{1-}$. ${ }_{x} \mathrm{In}_{\mathrm{x}} \mathrm{As} / \mathrm{GaAs} / \mathrm{GaAs} \mathrm{QWs}$ are observed related to the $\mathrm{x}$-concentration value. The greatest essential difference between these models is the size of energy levels. We analyzed the potential height, the bound energy levels and the finding probabilities of the electrons in ATQW. In particular, we have
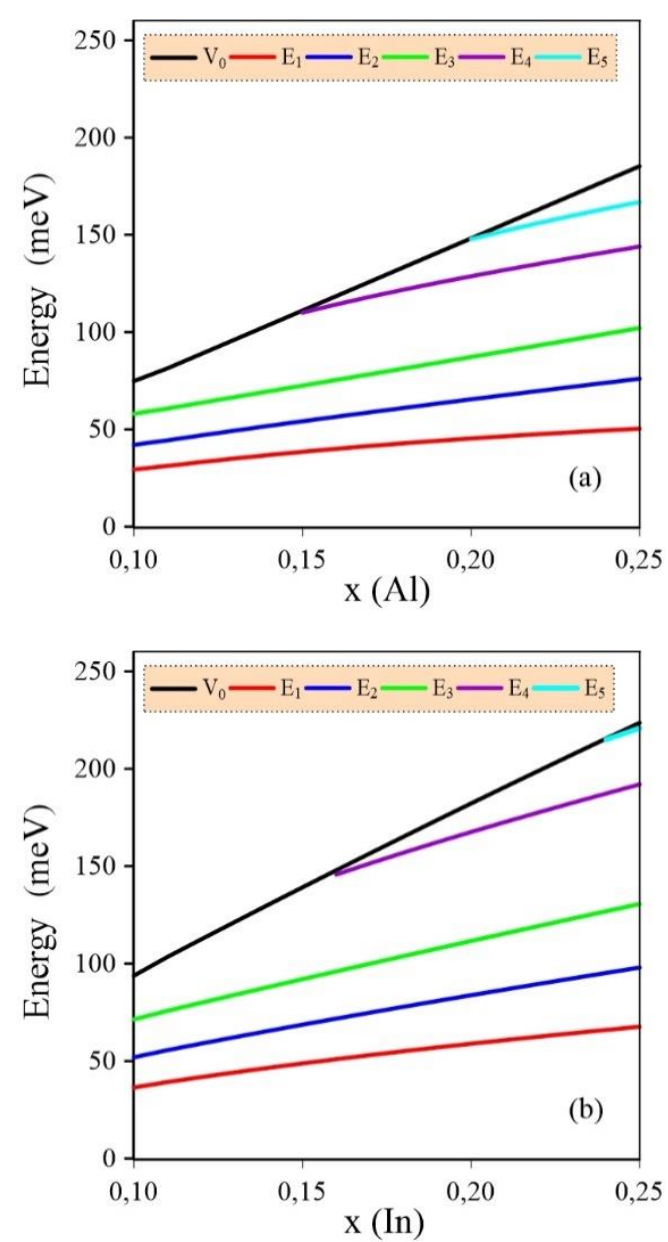

Figure 3. For ATQW the variation of the confined potential height and the bound energy levels versus the $\mathrm{x}$-concentration ratio values for a) A model, b) $\mathrm{B}$ model. 
calculated the eigen-energies and the eigenfunctions of these models. It is found that depending on the $\mathrm{x}$-concentration value of the electronic features of ATQW varies for A and B model. These features could be crucial in the improvement of continual wave operation of ATQW semiconductor devices. So, we think that these consequences will supply a development in multiple electro-optical semiconductor devices applications, for proper selection of the structural parameters.

\section{Acknowledgment}

This work is supported by the Scientific Research Project Fund of Sivas Cumhuriyet University under the project number M-679.
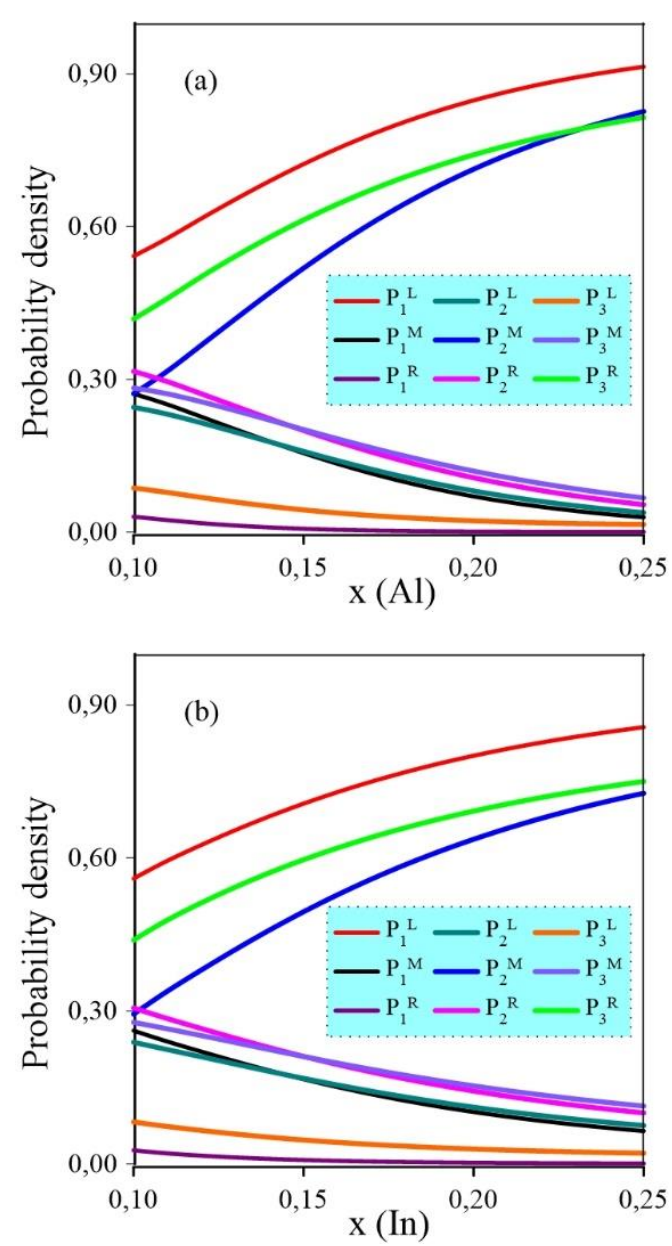

Figure 4. The probability density of the electrons in LQW, MQW and RQW for first three bound energy state as a function of the X-concentration ratios for a) A model, b) B model.

\section{REFERENCES}

[1] Zhao G. J., Liang X. X., Ban S. L., Binding energies of donors in quantum wells under hydrostatic pressure, Phys. Lett. A, 319 (2003) 191-197.

[2] Ozturk E., Simultaneous effects of the intense laser field and the electric field on the nonlinear optical properties in GaAs/GaAlAs quantum well, Opt. Commun., 332 (2014) 136-143.

[3] Raigoza N., Morales A. L., Duque C. A., Effects of hydrostatic pressure on donor states in symmetrical GaAs-Ga0.7A10.3As double quantum wells, Physica B, 363 (2005) 262270.

[4] Peter A. J., Navaneethakrishnan K., Simultaneous effects of pressure and temperature on donors in a GaAlAs/GaAs quantum well, Superlattice Microst., 43 (2008) 63-71.

[5] Ozturk E., Sokmen I., Nonlinear intersubband absorption and refractive index changes in square and graded quantum well modulated by temperature and hydrostatic pressure, $J$. Lumin., 134 (2013) 42-48.

[6] Kasapoglu E., Duque C. A., Mora-Ramos M. E., Restrepo R. L., Ungan F., Yesilgul U., Sari H., Sokmen I., Combined effects of intense laser field, electric and magnetic fields on the nonlinear optical properties of the step-like quantum well, Materials Chemistry and Physic, 154 (2015) 170-175.

[7] de la Cruz G. G., The influence of surface segregation on the optical properties of quantum wells, J. Appl. Phys., 96 (2004) 3752-3755.

[8] Martini S., Quivy A. A., Lamas T. E., da Silva E. C. F., Real-time RHEED investigation of indium segregation in InGaAs layers grown on vicinal GaAs(001) substrates, Phys. Rev. B , 72 (2005) 153304-153307

[9] Wu S., Huang Z., Liu Y., Huang Q., Guo W., Cao Y., The effects of indium segregation on the valence band structure and optical gain of GaInAs/GaAs quantum wells, Physica E, 41 (2009) 1656-1660. 
[10] Ozturk E., Electric and intense laser field effect on the electronic properties of Ga1xAlxAs/GaAs and Ga1-xInxAs/GaAs semiparabolic quantum wells, Laser Physics, 26 (2016) 096102-096110.

[11] Baser P., Altuntas I., Elagoz S., The hydrostatic pressure and temperature effects on hydrogenic impurity binding energies in GaAs/InxGa1-xAs/ GaAs square quantum well, Superlattice, Microst., 92 (2016) 210216.

[12] Fukuta, S., Goto, H., Sawaki, N., Suzuki, T., Ito, H., \& Hara, K., Modulation of optical spectra in an asymmetric triple quantum well structure. Semiconductor Science and Technology, 8(10) (1993) 1881-1884.

[13] Hernández-Cabrera A., Valance-band mixing effect on exciton dipole terahertz emission from asymmetric triple quantum wells, $J$. Appl. Phys., 80 (3) (1996) 1547-1552.

[14] Alaydin B. O., Ozturk E., Elagoz S., Interband transitions dependent on indium concentration in Ga1-xInxAs/GaAs asymmetric triple quantum wells, International Journal of Modern Physics B, 32 (5) (2018) 185500521855067.

[15] Ozturk O., Ozturk E., Elagoz S., Linear and nonlinear optical absorption coefficient and electronic features of triple GaAlAs/GaAs and GaInAs/GaAs quantum wells depending on barrier widths, Optik, 180 (2019) 394-405.

[16] Zorry P. S. Jr., Quantum well lasers, Academic Press, Boston: 1993; p.79.

[17] Niculescu E.C., Eseanu N., Spandonide A., Laser field effects on the interband transitions in differently shaped quantum wells, U.P.B. Sci. Bull., Series A, 77 (4) (2015) 281-292

[18] Ochalski T.J., Zuk J., Reginski K., Bugajski M., Photoreflectance studies of InGaAs/GaAs/AlGaAs single quantum well laser structures, Acta Physica Polonica A, 94 (1998) 463-467. 